\title{
Rereading Dam Street in the Chinese Cultural Context
}

\author{
Zhaohui Liu ${ }^{1}$, Yushan Zhao ${ }^{1} \&$ Hui Liu ${ }^{1}$ \\ ${ }^{1}$ North China Electric Power University, Beijing, China \\ Correspondence: Zhaohui Liu, 87\# English Department, North China Electric Power University, No.2 Beinong \\ Rd., Huilongguan, Changping District, Beijing 102206, China. E-mail: jas_liu@sina.com
}

Received: April 24, 2014 Accepted: May 21, 2014 Online Published: June 4, 2014

doi:10.5539/ach.v6n2p70 URL: http://dx.doi.org/10.5539/ach.v6n2p70

\begin{abstract}
As an emerging film director, $\mathrm{Yu} \mathrm{Li}$ has yet to be recognized by the international academic critics. By examining Hongyan/Dam Street in the Chinese cultural context with the assistance of analyzing scenes in detail and the film's visual style, this article argues that the film illustrates the protagonist Xiaoyun is stuck between traditions and modernity, providing a sophisticated insight to an important feminist issue. The reading of the traditions involves chastity code, the image of a rouge face which is the translation of the film's Chinese title, the Chinese four-character idioms, the time-honoured terms, the development of feminism, and the characteristics of the modernity in China. The perversity of the modernity originates from the social commercialization. Prejudices from the traditions and the modernity leave little space for women to settle in.
\end{abstract}

Keywords: culture, rouge face, traditions, modernity

\section{Introduction}

$\mathrm{Yu} \mathrm{Li}$ is an outstanding feminist director in mainland China as "we are challenged to rethink feminism under local/global conditions (Cui, 2011, p. 230)." Her film works include Jinnianxiatian/ Fish and Elephant (2001), Hongyan (Trans. Rouge Face)/ Dam Street (2005), Pingguo/ Lost in Beijing (2007), Guanyinshan/ Buddha Mountain (2010) and ercibaoguang/ the $2^{\text {nd }}$ Exposure (2012). All her films focus on women's struggles from a feminist perspective. These films have won a number of domestic and international awards and critical acclaim, as well as caused controversy. The most influential director in China Yimou Zhang compares her $2^{\text {nd }}$ Exposure to the U.S. film Black Swan and comments that she is a very ambitious director. However Dam Street stands out in her oeuvre and has drawn the most critical attention in mainland China.

From the very beginning Yu Li thinks globally while directing her films locally. She removes what she believes to be barriers to the understanding of foreign viewers. In an interview after the release of Dam Street she said she had deleted some details such as cyasma on the face of a pregnant woman because only Chinese people recognize it as a symptom of being pregnant ( $\mathrm{Li} \& \mathrm{Yu}, 2006$, p. 34). She had adopted the concept of zhuliuyishudianying/the mainstream art film, proposed by the producer Fang Li, and put self-expression and originality into second place so that the movie could be well accepted domestically and internationally (Li \& Yu, 2006, p. 37).

The story in Dam Street, however, takes place in a rural social setting, a major carrier of Chinese traditional values. Contrary to her expectations, it is still not easy for her film to be understood and interpreted fully within the Chinese cultural context. The western media commonly misinterpret the setting. Elley writes on Vatiety,

Paragraphed by a handful of intertitles that fill in dramatic gaps in the story, film has a remote, mannered feel that -- unlike Li's previous movie -- never gets to the heart of the drama. For starters, Xiaoyun's dream of becoming a proper Sichuan opera performer (referred to in the pic's Chinese title,"Rouge Face") is never developed as a parallel thread, despite thesp Liu being an actual graduate of the art (2005).

Dargis asserts on the New York Times, "Xiaoyun takes to the boy with tenderness that wavers perilously from the maternal to carnal, and makes the film's melodramatic denouement all the more transparent" (2007).

Elley's failure to understand the connotation of the film's Chinese title "Rouge Face" leads to her inability to appreciate the film's theme. Out of the western perspective of hunting for novelty and excitement, Dargis interprets the relationship as something different from what the Chinese audience can see. Both of them fail to understand the movie within the Chinese cultural context. Actually, few western critics could combine the 
reading of this film with a thorough understanding of its set. Nevertheless, Dam Street is neither about a woman's successful career nor about the sensational incest. It portrays a Chinese woman stuck between dying-hard traditions and the perverse modernity. The road for the west to understand Chinese movies may be as long as Chinese movies competing for the Best Foreign Language Film of Academy Awards. In this article I integrate the knowledge of the Chinese culture, including the traditional beliefs, four-character idioms, time-honoured terms and the development of feminism in China with detailed analysis of relevant scenes of the film to demonstrate my point of view.

\section{Synopsis}

Dam Street, shot in Sichuanese, follows the life of Xiaoyun, a young woman in a small town of Sichuan province. The story begins with a teenage girl Xiaoyun in loose clothes sitting in the water of a river. She looks confused and lost. She is a senior middle school student in the early 1980s when China is starting its opening up policy. She has a swelling belly though she tries to hide it. Consequently she and her boyfriend Feng Wang are expelled from school for their moral decadence. The scandal is made known to everybody on a school loudspeaker. The boy flees to a faraway place. Xiaoyun stays and delivers a baby, which her mother says is dead. Ten years later still living in shadow, she works in a troupe as an opera actress reduced to dressing sexy and scantily on stage singing pop songs. She is also subjected to sexual advances; and has an affair with Wanjin Liu, a married man in the same troupe. Only a ten-year-old precocious boy Xiaoyong worships, cares about and sometimes protects her. Responding with hope and gratitude, Xiaoyun develops a mute attachment to the little boy. But when she gets to know he is her son who is adopted and raised by the sister of Feng Wang, she chooses to leave the town.

\section{Traditional Ethics of Chastity}

Xiaoyun's mother is a representation of the traditional force since she is a patriarchal figure. She punishes Xiaoyun with a feather duster, a traditional tool of domestic punishment in China; when Xiaoyong plays a trick on a female student, pulling a string that breaks down her sweater revealing her belly, she as his teacher, punishes him by beating his hand with a teaching stick, traditionally used as a warning or threat to students; these scenes establish her as a traditional patriarchal figure. The following scene fully displays the dominant assumption of the traditional ideology that the mother represents:

The first shot is a close-up of a man's old photo with amber tone on the wall. The man we see in profile wears a pair of glasses and has an authoritative look. Then we hear a noise. The camera cuts to a wide-angle panorama and offers a stationary view of Xiaoyun, her mother and the serious-looking man in the photo. Her mother raises high a feather buster in her hand and hits her hard on the back. She falls and kneels in front of the photo. Her mother points to the photo and screams hysterically, "Tell your father what you have done!"Xiaoyun sobs speechlessly. Her mother pounds at a desk with the duster and roars that the scandal spreads over the school and the town. "You are shameless. I can't be. You're shameless." Repeating this sentence numerous times, her mother whacks her nonstop with the duster. Xiaoyun writhes and crawls everywhere for a hiding place. As she staggers blindly, she knocks off a small fish tank on the desk. The tank breaks and the golden fish are flopping desperately on the floor. Wherever she runs, her mother goes after her with sticks falling on her like raindrops. Her groaning and screaming is intermingled with her mother's continuous curse that she is shameless. Mother shows no tendency to stop beating until she holds a kitchen knife against her neck.

The scene consists of two shots. The second stationary shot lasts one minute. The long take is a cold gaze for emphasize the disturbing scene. First, the shot of the man on the wall and the mother pointing to the photo establish her as a patriarchal woman who utters the traditional value. Second, her madness and anger and hysteria are highlighted and the reason behind her insanity is revealed through her language. The word "shameless" she repeats again and again carries cultural implication and accounts for the madness of the mother. It is the concept of chastity and virginity that separates the mother and the daughter psychologically and physically. The out-of -marriage sex of a young girl is considered as deviant and subversive, and must be forbidden in the society. As a mother, she should embrace her daughter who is humiliated and kicked out of school. However breaking the chastity code is the last thing the mother can accept and consequently Xiaoyun is not only disgraced and exiled by school but also by her mother.

Though the concept of chastity and virginity can be seen in all cultures in the world it is even more of a determining power in the formation of Chinese people's mentalities. That is closely associated with Chinese philosophies and Chinese history. The thought of Confucianism has ruled China for thousands of years though it has experienced a beginning, peak and revival. The fall of women's political position parallels the legitimization of Confucianism. The moral ethics advocated by Confucians is to defend and safeguard male dominance. The rise of Confucianism occurred during the Spring and Autumn and the Warring States (770BC-476BC). At this 
time the concept of chastity was proposed in Confucian classic books. Li Ji/ The Book of Rites says, "Once a woman gets married, there is no chance for change. She can't remarry after her husband dies." According to $Y i$ Jing/ The Book of Change, "Women's chastity requires that she be faithful to a man unto death." In the Chinese Song (960-1279) and Ming (1368-1644) dynasties, Confucianism evolves into a new stage. The Chen-Zhu School, known in Chinese as chengzhulixue, is one of the major philosophical schools of neo-Confucianism, based on the ideas of the Neo-Confucian philosophers Yi Cheng, Hao Cheng and Xi Zhu. The propositions put forward by Yi Cheng and Xi Zhu are well-known to Chinese people and have been highly influential in shaping the society. Yi Cheng says starving to death means very little while women's loss of chastity means very much. Xi Zhu champions destroying humanity to save rationality. Any human desire, sexual desire specifically, should be banned. In reality, this is imposed on women unilaterally. Yuanzhang Zhu, an emperor in the Ming Dynasty, issues an edict that if a woman turns into a widow before the age of 30 and refuses to remarry till 50 years old, her family should be awarded the exemption from slave labour. The law in Qing Dynasty (1616-1911) stipulates that a widow who keeps chastity from less than 30 years old through to 50 years old should be named a chaste woman; a woman who takes her life when confronting a family misfortune or raping should be named a heroic woman; a girl who, on hearing the death of her fiancé, takes her life or cries and hurries to practice chastity at his residence, should be named a wise virgin. With the concerted efforts of many dynasties, the ethics and concepts of chastity preached by Confucians are universally recognized as the social moral standard and become the major beliefs and codes of conduct of women (Wang, 2009, pp. 36-43).

The relay of chastity proceeds to the contemporary society and the moral standard is still being reinforced in the film, which is demonstrated by the mad mother as well as the authorities in school which punish Xiaoyun to consolidate the rule shown as in the next scene. Different parties of the society form a gripping network to punish those who dare defy the conventions. The school is children's first and foremost social environment and a pass to the society of the future. When Xiaoyun is deprived of her rights of education, her space shrinks dramatically and her future becomes uncertain and unpredictable.

This scene begins with a cheerful and passionate song which goes, "Dear friends, to whom does this spring belong?'Inspired by the upbeat music, young students abounding in vigour and vitality are flooding onto the playground. And very soon the camera cuts to a close-up featuring a loudspeaker in silver color fastened high onto a wooden post by the playground. The loudspeaker overlooks and dwarfs the playground, the school and the town beyond. The song proceeds, "It belongs to you and me, and the new generation of the 1980s." In the midst of open and pleasant mood, the playground takes on a dynamic picture with some students jogging, some jumping ropes, some chasing one another and others playing basketball. But the noisy and jubilant scene comes to a halt when a man on the loudspeaker clears its voice and asks for attention. The students are standing there and looking up to invisible force and listening. The powerful male voice $\mathrm{r}$ proclaims,

Feng Wang and Xiaoyun Liu, two senior middle school students, have committed moral decadence for having sex leading to pregnancy. They have caused a very bad negative impact on the school and the society. And what's more, they have violated the code of conduct for middle school students. With the school leaders' deliberation, it is decided that both of them be expelled from school.

As the authoritative voiceover is echoing down the school and the town, the camera cuts to Xiaoyun walking alone in a street. As the camera pans along the street with Xiaoyun in the foreground and the dark and old street and the faceless men as the background, it displays vividly how the beliefs and attitudes held by people are shaped and dictated by the propaganda and the statement broadcast from the loudspeaker. She looks timid; the men in the background sneer or laugh at her, taking her as a flirt.

In this scene the loudspeaker can be read as the state-controlled media or the dominant ideology. The sequence reveals the hypocrisy and the controlling power of the state media. The songs and music broadcast on the loudspeakers are usually carefully selected and are supposed to advocate the mainstream culture. This song sounds very encouraging and promising as if it is ushering in a new carefree future to the new generation. But the later announcement is a contrast and an irony to the preceding song. The announcement is a conviction, a reminder of the chastity ethics and the shackle on women for thousands of years. Its vocation is to kill and destroy life and hope. This mirrors the reality in mainland China and it is a response to the emotional resonance at the time. After the practice of Opening up and Reform since 1978, people have been looking forward to a better life, only to find that the new life promised by the state policy is merely an empty talk. Furthermore, the state media is so powerful that everybody and everything seems in its firm grip. When the song plays, the playground is a bright and throbbing image that resembles a garden returning to life as spring returns. When the announcement is made, the camera displays a dark and static and desolate look. Xiaoyun withers, withdrawn and forsaken. She is castigated as a bad woman and carries this stigma for a life time. Even Feng Wang thinks of her 
as a bad woman after this "conviction" is made known. When Xiaoyun is deserted and shunned by her mother, her friends, the school and the society, she turns to him who impregnates her. As she sees him, his initial response is asking if they are still friends. He means to be just an ordinary friend. If a Chinese man offers to be a friend, it means he doesn't want a relationship and just wants to keep a distance from the other. He wants to stay away from her, a disgraced woman. He has bought a train ticket to leave for a faraway place. And he believes he has cleansed himself by asking his nurse sister to make a forced premature $\mathrm{C}$-section for her. He is eager to do away with the shame and correct the mistake he has made.

\section{Traditional Image of Rouge Face}

Xiaoyun has a rouge face both as a teenager and as an adult. The camera first shows her rouge face with two red spots on cheeks when she sits at a meeting for performing as an amateur actress and passes Feng Wang a slip of paper with words "I am pregnant". And again with the time passage of ten years the camera reintroduces her identity as an adult by a close-up of her rouge face with heavy makeup. At this moment she becomes a leading professional actress in the Sichuan opera troupe.

Literally a rouge face is a woman's face with pink or red powder coloring the cheeks and lips. The connotations and allusions of a rouge face are myriad. They may be embodied in three well-known Chinese four-character idioms. The first one is Hongyan zhiji which means a pretty woman is an ideal candidate for extramarital love. The second is Hongyan boming which means pretty women end miserably. The third is Hongyan huoshui, literally "a rouge face is a flood of evil". They are common motifs in Chinese folk tales, legends, epics, and literary works which endeavor to convince readers that pretty women are the objects for desire but involvement with them will result in the falling of cities and nations, a Chinese version of the Western Helen of Troy. The idioms, miniatures of traditional culture, reflect men's psychology that while they yearn for pretty women and desire for satisfaction from them, they are restricted by moral standards and turn to blame women for breaking the chastity ethics. Thus women are used first as sexual spectacles to please men and then as scapegoats held for accounts and therefore should be punished. When a rouge face's profession is to entertain the audience, the term comes to carry the stigma of a prostitute (or men's plaything) and a general contempt towards her. When a rouge face is degraded into a quasi-prostitute, it is more convenient for men to keep women at their mercy in that they don't have to feel guilty and seek any excuses for their dissolute behaviors since prostitutes do not have any human rights and do not deserve any scruples.

Xiaoyun is a leading actress in the Chuanese opera troupe. A leading female opera performer is termed as Hua Dan. It is defined as a vivacious woman, a coquette in a play. The term first appeared in Qinglouji/Collections of Women Artists in Brothel by Tingzhi Xia (1300-1375), a playwright of the Yuan Dynasty. He noted a prostitute with a full makeup of rouge, powder and ink is to play Hua Dan ("Hua Dan", 2014). In light of the connotation and implication of the terms, the film's Chinese title Hongyan (Trans. As Rouge Face) will never indicate an ideal career for a woman as suggested by Derek Elley on Variety.

Rouge face translated as "to powder the face" in the poem "Militia Women" written by the founder of People's Republic of China Zedong Mao is an image representing women's subordinated status and a trash to be eradicated for women's rebirth. The following is the poem by Zedong Mao,

So bright and brave, with rifles five feet long,

At early dawn they shine on drilling place.

Most Chinese daughters have desire so strong,

To face the powder and not to powder the face (1993, p. 88).

The following scene demonstrates clearly that Xiaoyun is treated as a visual and sexual spectacle and risks the tendency to be degraded into a plaything. Ten years after her expulsion from school she is performing on the stage of a Chuanese opera house. The first shot is a long close-up: a beautiful and vivid young woman's face with red cheeks and lips (literally a rouge face). She is singing melodiously and enthusiastically. Her appearance changes as boos are coming from the audience. Then rise men's shouts, "Not this! We want pop songs! Sing 'As Tender as You Are'!" A man rushes two accompanying girl dancers onto the stage behind Xiaoyun. "Strip yourself! Remove your clothes! Remove your clothes!" men shout loudly. She looks defiant. As the music starts, she lifts her mike and sings the song passively as commanded. At this point, the camera is zooming out for a wide-angle shot. The audience's backs come into the frame and get united as a black threatening mass. The stage shrinks into a faint pale spot. At this moment, the cinematography is mainly in black and white. Though the swaying singer and the pleasure-seeking audience being there is a present tense, the image seems from long ago and far away. It is a reminder of the long Chinese male-dominated history. 
The cinematography is characterized by close-ups for the protagonist and wide-angle shots for the men. Close-ups help connect the audience with Xiaoyun who does not speak much and whose expression reveals her confusion. Men are never given a focal point and they are almost faceless. The contradictory tension extends to the stylistics of the film. They are shot as if through the eyes of a woman and they represent an impression or a memory about the timeless corporate culture of male dominance over and degradation of women. Irony and disharmony mark this scene and the criticism is obvious. An opera performer in opera costumes singing a pop song on stage is revealing in that an opera stresses listening while the pop embodies more visual and sexual pleasure; the two unskilled and blank-looking dancers are there to be gawked at. Xiaoyun being treated as a public pleasure is evidenced by Xiaoyong as well. He and his friend coax a dozing watch man into giving them an access into the theatre to catch a glimpse of the "modern" Chuanese opera, which the watch man remarks as inappropriate for children. Through adolescent gaze, Xiaoyun is a public sexual pleasure on the stage wearing scantily and swaying coquettishly and singing "Don't pick wild flowers on the wayside", figuratively meaning shunning extramarital affairs, while the audience including these two boys chant slogans "No way". Off the stage, the two boys see her flirt with Wanjin Liu who tells her that his wife is gone for a few days he will see her at the old place. On the way to buy food, Xiaoyong's friend tells Xiaoyong that his grandpa says Xiaoyun is a loose woman though the comment is strongly confronted by Xiaoyong. A loose woman is pronounced clearly and emphatically on quite a few occasions in Chuanese dialect as suoxiezi (literally a worn-out shoe), which serves to mirror the life of the rouge face Xiaoyun in the film. That helps to understand the shot of Mr. Qian raising his two fingers to Xiaoyun at her dormitory, "Two hundred RMB for a night?" This is a prototypical image in films: a man is striking a deal with a prostitute.

\section{Perverse Modernity}

Though Chinese Socialist state is seen as a women-friendly one and plays a key role in advancing the rights and status of women, feminism is not well accepted and even the director Yu Li denies being a feminist. Since 1945, the Chinese communist party has adopted a series of measures to promote social reforms: abolishing arranged marriages, closing brothels, reforming prostitutes, encouraging women to leave the domestic sphere and enter the work force. The Chinese government has also promulgated laws to ensure equal remuneration for men and women workers. But this women's liberation movement is rather a top-down reform than an achievement of women's awakening and struggles. A women's cultural revolution that should have happened to doubt and challenge the male-dominating society has never occurred. Though legally Chinese women's social status is high, the gender-consciousness is very low (Dai, 1999, pp. 138-139). The Chinese feminism and the women's movement have not developed into a mass-participation political movement. Furthermore, in developing countries, consolidation of social stability is the primary goal of the government, so any issues identified as undermining the existing values, including feminism, are discouraged from being published in the media (Yang, 2009, p. 99).

When asked about people's response to the translation and introduction of Simone de Beauvoir's The Second Sex, the feminist Jinhua Dai explains, "What readers see is sex not feminism (Cui, 2003, p. 172)." Shuqing Cui argues about the theme of the film Dam Street, "The film critiques a society dominated by sex and commerce, where women find neither space to settle down nor men to trust (2011, p. 223)." How does China come to be dominated by sex when it has been shaped for thousands of years by Confucianism which champions chastity ethics? Clues are given in the film to answer the question. Shenzhen which is mentioned a few times though never appears in the film is established as a contrasting space outside of the small rural town to represent an open and commercial city as it is the first Special Economic Zone in China. Xiaoyun's friends chat around the table and talk of some women who have gone to make a living in the city and end up as prostitutes. Xiaoyun's best friend Mimi goes to Shenzhen eventually. The influence of commerce on women is direct: they sell their sex for money. Though Xiaoyun resists the idea of sex for money, she is classed as such by people represented by Mr. Qian who asks her why she would think about marrying a poor man and by Jin's wife who can't understand Xiaoyun's sexual relationship with her poor husband. On the other hand as part of the consequence of the market economy, money empowers and emboldens the rich men to buy sex. Mr. Qian represents a powerful man in the film: men speak as a sycophantic toady to him and women hold the fantasy of marrying him for protection. It is made explicitly in the film that his power comes from money. That is emphasized by his name, the ornaments on his body, cinematography and his own language. His surname Qian means money; the gold chain on his neck and a close-up of his wallet indicate his wealth; he asserts, "I am an entrepreneur. I have power, fame and money. I have everything that is good in the world. And I can get whatever I want." Yu Li's subsequent film Pingguo picks up where Dam Street leaves off and continues to explore women's sexuality in the urban set. Shuqing Cui's remark about lost in Beijing is that "As the market economy turns migrant bodies, male and female, into 
commodities in the accelerating urbanization of China (2011, p. 229)." At this historical transitional point of this rural town where the chastity concept still lingers and an old rouge face risks the transformation from a sexual spectacle into a commodity, the director Yu Li records the perversity, confusion and chaos of the modernity as demonstrated in the next scene:

The scene adopts a melodramatic mood and a half-documentary tone. We first see a close-up of Xiaoyun's rouge face. She is dressed in a red qipao/cheongsam, a body-hugging traditional Chinese dress for professional women to wear on important occasions. She is singing a pop song on an open stage, "Modern people admire money and seize love firmly. But they hate to talk about marriage. They want love and bread, houses and jewelry. Good looks don't last long." The camera then zooms out to a panoramic view of the stage and its background. The stage is set at the corner of a street to celebrate the opening of a department store, the front facet of which is decorated gaudily with flags and scrolls and banners flaunting its business and attracting customers. The back of the stage is packed with boxes of awards and gifts. An audience assembles in front of the stage to watch the show. Suddenly a man's angry voice rises, "Mother and sister, there is the witch. Beat her to death!" The man and two women followed by a boy cut their way through the crowd and charge onto the stage and pounce at Xiaoyun. Her co-workers come to her rescue but are heckled to get away. She is crushed down onto the floor and bitten by the two women. The ferocious man is addressing the audience loudly, declaring that Xiaoyun is a whore and deserves death and nobody can intervene. The little boy is stoning her while yelling she is a loose woman seducing his father. One of the two women screams hysterically that Xiaoyun is shameless for luring her husband Wanjin Liu. Then an overhead shot shows Xiaoyun with two hands covering her face lying motionless on the red carpet as if in a pool of blood. Then another close-up shows her rouge face with closed eyes and disheveled hair and torn clothes, and then her opening her eyes and getting to her feet. A long shot follows her walking slowly and inexpressively through the crowd of spectators.

The sequence displays the coexistence of the tradition and the modernity. The latter is marked by the song's content and commercial images: boxes of gifts, the department store and the huge poster of suits. As Xiaoyun is the leading performer promoting the sale and singing a song foregrounding wealth and sex, from the perspective of the audience, she comes to represent the material girl and in a deep level a woman who may sell sex for money and thus is potentially targeted to pay a price. The former is embodied in the collective assault and the spectators' indifferent response. Xiaoyun is accused of committing adultery and dismissed as a witch, a loose woman and a seducer, and therefore must be stoned to death, a reminder of her breaking the chastity code and serving as a scapegoat for this affair. What's more the spectators tolerate and accept "the punishment of the bad woman." In this sequence the camera captures the response of ordinary people; life and art catch up. The spectators are not purposely arranged and have not been rehearsed. When the attack is under way, people watch interestedly and listen attentively to the protest of the belligerent family. People even smile and whisper, satisfied with the fact that the wicked woman is brought into justice. The assault of the family and the response of the ordinary people reveals how pervasive and powerful the traditional concepts are in the society, and how women's state is complicated and worsened in this modern society.

\section{Conclusion: An Open End}

With a detailed analysis of the scenes of the film by placing Dam Street in the Chinese cultural context, we can see Xiaoyun struggling in the mire of the traditions and the sick modernity. In light of the traditions, women should follow the chastity code and paradoxically pretty women, i.e. rouges faces, are expected to offer visual and sexual pleasure to men, and to prepare to take all the blame. As the society gets increasingly commercial, women are made more vulnerable to the power of money. However the director doesn't simply depict her protagonist as a victim and make moral judgments. She raises the spectator's awareness of women's issues as well as awakening and empowering the main female character to challenge tradition and explore her position. Xiaoyun stabs Mr.Qian at her wedding banquet; she annuls her marriage with Wanjin Liu; she doesn't claim Xiaoyong as her son; and she decides to leave the town. Yet the foggy hills, the cloudy weather and the vaporous babbling river symbolically allude to no ultimate resolution. The alternate use of close-up and tracking long shots wordlessly suggest Xiaoyun's losses and helplessness and despair in adversities of career as well as life. The revelation of the true relationship between Xiaoyun and Xiaoyong, mother and son, reinforces the mood of loss that blankets the whole movie. Responding to the inquiry in an interview about the symbolical meaning of the Chinese title Hongyan (trans. as Rouge Face), Yu Li says, "This term makes people think a lot. She lives as a rouge face in the public and experiences the hardships that a rouge face involves in this world. Everything seems justifiable in this fair society. But the ending makes the movie full of hope when she leaves the town to look for her spiritual garden to relocate her soul (2005)". 


\section{Acknowledgments}

This research was supported by the Fundamental Research Funds for the Central Universities (North China Electric Power University, 2014ZD25).

\section{References}

Cui, S. Q. (2003). Women through the Lens: Gender and Nation in a Century of Chinese Cinema. Honolulu: University of Hawai'i Press.

Cui, S. Q. (2011). Searching for Female Sexuality and Negotiating with Feminism: Li Yu's Film Trilogy. In L. Wang (Eds.), In Chinese Women's Cinema: Transnational Contexts (pp. 213-223). NY: Columbia UP.

Dai, J. H. (1994). Bu kejian de nvxing: dangdaiZhongguodianyingzhong de nvxingyunvxingdianying/ Invisible women: Contemporary Chinese cinema and women's film. Dangdaidianying/Contemporary Cinema, 6, $37-45$.

Dai, J. H. (1999). Youzaijingzhong/As if in the Mirror. Beijing: Knowledge Publication Company.

Dargis, M. (2007, May 17). Rejected by Society, a Woman Struggles to Carry on. Retrieved December 5, 2013, from http://movies.nytimes.com/2007/01/17/movies/17hong.html?_r=0\&pagewanted=print

Elley, D. (2005, September 13). Dam Street. Retrieved December 1, 2013, from http://www.variety.com/review /VE1117928177/?refcatid $=31$

Hua, D. (2014, February 25). Retrieved March 12, 2014, from http://baike.baidu.com/subview/41622 /7766990.htm

Li, Y. (2005, August 12). Li Yu - xianru jingshen kunjing de Zhongguonvren/Li Yu - a Chinese Woman in Spiritual Dilemma. Retrieved October 16, 2013, from http://yule.sohu.com/20050812/n226652624.shtml

Li, Y., \& Guan, Y. D. (2006). Nvxingshijiaoxia de shisuyanshuo - Li Yu fangtan/ A Worldly Tale from the Perspective of a Feminist - an Interview to Li Yu. Dianying yishu/Cinema Art, 1, 34-37.

Mao, Z. D. (1993). Selected Poems of Mao Zedong (Trans. Xu Y. Z.). Beijing: China Translation \& Publishing Corporation.

Wang, R. Y. (2009). Rujialijiaoyufunvdiwei de bianyuanhua/Confunianism Politeness and the Marginalization of Women's Position. Shehuikexuejia/Social Scientist, 10, 36-43.

Yang, C. (2009). Negotiating fragmented women's news: State, market and feminism in Contemporary Chinese media. Asian Journal of Communication, 19(1), 97-115. http://dx.doi.org/10.1080/01292980802618510

\section{Copyrights}

Copyright for this article is retained by the author(s), with first publication rights granted to the journal.

This is an open-access article distributed under the terms and conditions of the Creative Commons Attribution license (http://creativecommons.org/licenses/by/3.0/). 